\title{
O triângulo da formação docente: seus jogadores e confi- gurações*
}

\author{
Flavia Medeiros Sarti \\ Universidade Estadual Paulista
}

Correspondência:

Flavia Medeiros Sarti

Instituto de Biociências - UNESP

Departamento de Educação

Av. 24 - A, n. 1515

13506-900 - Rio Claro/SP

fmsarti@rc.unesp.br

* Este trabalho vincula-se ao Projeto CNPq intitulado Mercado de formação docente: constituição, funcionamento, possibilidades e limites, o qual, por sua vez, integra o Projeto Temático FAPESP Programas Especiais de Formação de Professores, Educação a Distância e Escolarização: pesquisas sobre novos modelos de formação em serviço.

\section{Resumo}

0 artigo tem por tema a formação dos professores que atuam nos anos iniciais da educação básica, considerando-a como um jogo que assume diferentes configurações em função das relações estabelecidas entre seus jogadores. Essas relações são analisadas por meio de um esquema de triangulação, aqui denominado como triângulo da formação docente. Cada um dos três vértices desse triângulo é ocupado por agentes que, a partir de seus capitais específicos, localizam-se em lugares desiguais no campo da formação docente: os professores e as instâncias que os representam; as universidades, fundações e institutos de pesquisa, com seus especialistas; e o poder público, representado por secretarias de educação e outros órgãos administrativos. Relações privilegiadas entre dois vértices do triângulo da formação docente apontam para diferentes modelos formativos. Explorando esse triângulo como um recurso de análise, o artigo focaliza as configurações assumidas pelo jogo da formação docente na versão brasileira do movimento ora em curso de universitarização do magistério. Atenção especial é conferida ao lugar que os professores atuantes nos anos iniciais da educação básica ocupam nesse jogo, às relações que eles estabelecem com os demais jogadores e, também, às possibilidades que têm de subverter e alterar o jogo em andamento.

\section{Palavras-chave}

Formação de professores - Universitarização do magistério - Campo da formação docente - Profissão docente. 


\title{
The triangle of teacher education: its players and configu- rations*
}

\author{
Flavia Medeiros Sarti \\ São Paulo State University
}

\section{Contact:}

Flavia Medeiros Sarti

Instituto de Biociências - UNESP

Departamento de Educação

Av. $24-A, n .1515$

13506-900 - Rio Claro/SP

fmsarti@rc.unesp.br

* This work is linked to do CNPq project The market of teacher education: constitution, functioning, possibilities, and limits, which is part of the FAPESP Theme Project Special Programs of Teacher Education, Distance Education and Schooling: studies on new models for in-service education.

\section{Abstract}

The article has as its theme the education of teachers working at the initial series of basic education, regarding it as a game that takes on different configurations as a function of the relations established among its players. These relations are analyzed through a triangulation scheme, here denominated the triangle of teacher education. Each vertex of this triangle is occupied by agents that, based on their specific capitals, are placed in uneven locations within the field of teacher education: the teachers and the bodies that represent them; the universities, foundations and research institutes, with their experts; and the public authorities, represented by secretariats for education and other administrative sectors. Privileged relations between two vertices of the triangle of teacher education point towards different formative models. Exploring this triangle as an analysis tool, the article focuses on the configurations adopted by the game of teacher education within the Brazilian version of the universitization movement of the teaching profession currently underway. Special attention is given to the place occupied in this game by the teachers working at the initial series of basic education, to the relations they established with the other players, and also to the possibilities they have of subverting and changing the game in play.

\section{Keywords}

Teacher education - Universitization of teaching - Field of teacher education - Teaching profession. 
Em que pese a crescente atenção que temos dispensado aos professores da escola básica - procurando conhecer melhor as bases epistemológicas de seu trabalho, elevando sua formação ao nível superior e buscando caminhos para a profissionalização do magistério -, eles seguem às margens do campo educacional, atuando como referenciais passivos tanto de pesquisas acadêmicas quanto de políticas públicas e, também, como consumidores no amplo mercado formativo a eles dirigido (NÓVOA, 1999a; MAUÉS, 2003; SOUZA; SARTI, 2009). Muito se tem produzido sobre, pelos e para os professores, sem que isso lhes possibilite alcançar posições mais centrais no campo da educação e obter melhores resultados nas disputas nele empreendidas.

Assim, as interessantes informações sobre os saberes docentes, reunidas nas últimas décadas por meio de pesquisas acadêmicas, não têm possibilitado aos professores aperceberem-se melhor de seus próprios saberes (NÓVOA, 1999b). Do mesmo modo, a profissionalização da docência (BOURDONCLE, 2000), norteadora de políticas educacionais que alteram significativamente o trabalho, a formação e a carreira docente, não resulta de uma movimentação interior ao magistério, posto que integra um amplo movimento de reformas dirigido por organismos internacionais (MAUÉS, 2003; BELLO, 2008). Aos professores resta consumir os produtos - inclusive de natureza discursiva - do aquecido e rentável mercado da formação docente, voltado a transformá-los em profissionais reflexivos, autônomos e eficazes.

Diante desse contexto, e fundamentando-se em revisão de literatura sobre a temática da formação docente, o presente artigo discute o lugar - nem sempre evidente - que os professores ocupam nos movimentos atuais que buscam reinventá-los (BUENO, 2007). Considerando tal posição assumida hoje pelos professores, são apontadas algumas possibilidades de configuração do jogo da formação docente.

\section{Os professores entre o consumo de produtos formativos e a expertise prática}

Um movimento de profissionalização docente vem assumindo destaque no campo educacional nas últimas décadas, apresentando-se como principal caminho para o empowerment (empoderamento) dos professores, ou seja, para torná-los mais autônomos e responsáveis pelo andamento dos trabalhos na escola. E a fim de profissionalizar os professores, considera-se necessário elevar o nível de sua formação de modo a iniciá-los em valores, práticas e saberes acadêmico-científicos. Raymond Bourdoncle (2000) explica que a universitarização do magistério vem atuando como importante dispositivo para que a docência ultrapasse o status de mero ofício, baseado em saberes de ordem prática aprendidos pelos professores na experiência direta do trabalho cotidiano e/ou na relação com seus pares. Essa universitarização da formação docente ancora-se no pressuposto de que o contato dos professores com saberes acadêmicos lhes proporcionaria aproximações mais racionais, reflexivas e críticas com a prática pedagógica, de modo a favorecer o desenvolvimento de competências específicas que lhes possibilitariam uma atuação mais eficaz. Nesse contexto, como observa Maurice Tardif (2002), a questão epistemológica assume uma posição central, de modo que as profissões, diferentemente do que ocorre com as demais ocupações, devem apoiar-se em conhecimentos especializados e formalizados, adquiridos por meio de uma longa formação de alto nível, universitária ou equivalente.

Ao longo do século XX, diversos países empreenderam reformas educacionais que previam a elevação do nível de formação dos professores das séries elementares. Esse é o caso dos Estados Unidos na década de 1930, do Canadá e da Inglaterra nos anos 1960, da Austrália nos anos 1970, do México na década de 1980 e da França nos anos 1990 (BOURDONCLE, 2000). Mais recentemente, a Comunidade Europeia estabeleceu que 
a formação de seus professores deve ser elevada ao nível de mestrado, totalizando cinco anos de estudos universitários, como já ocorria em alguns países do norte da Europa (CHARTIER, 2010).

No que se refere especificamente ao contexto brasileiro, a elevação do nível de formação dos professores que atuam nos anos iniciais foi impulsionada pela Lei de Diretrizes e Bases da Educação Nacional (Lei $\mathrm{n}^{0}$ 9.394), de 1996. Ao preconizar a formação superior para todos os professores da educação básica, tais diretrizes legais resultaram em um movimento de ampliação da oferta e da procura por cursos de pedagogia ou de normal superior, ambos voltados para a formação docente.

Além das ações individuais assumidas por muitos professores, o cumprimento das disposições apontadas pela referida LDB vem motivando vários Estados e municípios brasileiros a adotarem estratégias específicas para a formação em nível superior de seus quadros docentes. Muitos deles buscam firmar parcerias com universidades para a criação de programas especiais de formação que possibilitem diplomar, de uma só vez, grande número de professores em serviço; isso sob condições específicas caracterizadas, sobretudo, por limitações de tempo e de espaço e pela redução dos recursos financeiros empregados. Assim, em todo o país, milhares de professores em exercício integram os quadros discentes do ensino superior, seja em cursos regulares de licenciatura, seja em programas especiais de formação docente em serviço.

Tal como ocorre no contexto internacional, essa elevação do nível de formação dos professores brasileiros é acompanhada por discussões sobre a estrutura e o currículo dos cursos de licenciatura. Em tais discussões, evidencia-se a importância da experiência prática para a formação como meio de preparar melhor os professores para o trabalho na escola e na sala de aula. É o que já apontavam, no final da década de 1990, os Referenciais Nacionais para a Formação de Professores ${ }^{1}$ :

1- Na década seguinte, o Ministério da Educação publicou diversos outros documentos referentes à formaçã̃o de professores (BRASIL, 2002, 2006 é preciso especial atenção ao fato de que a integração completa dos conhecimentos só ocorre realmente na atuação do professor e, portanto, é essencial garantir um espaço curricular prioritariamente comprometido com os conhecimentos experienciais contextualizados e com a construção de instrumentos para a intervenção pedagógica. (BRASIL, 1999, p. 113, grifos nossos)

Assim, ao lado da universitarização do magistério, que pressupõe acentuada valorização dos saberes acadêmico-científicos para a docência, assume destaque outro movimento, que coloca a experiência prática no centro da formação dos professores. Essas duas tendências, embora concorrentes em alguns sentidos, coexistem em certos contextos nos quais se buscou um caminho intermediário, capaz de aliar a elevação do nível da formação à ênfase na prática docente. Amplia-se, nesse sentido, o espaço reservado às experiências em espaços educativos - em forma de prática como componente curricular e de estágio supervisionado de prática de ensino - nas licenciaturas em que são formados os novos professores. No caso dos professores em exercício, aumentou substancialmente a oferta de formação superior em serviço, com o aproveitamento de sua experiência profissional docente, o que representa inclusive uma via mais barata e rápida para a universitarização, tal como recomendado pelo Banco Mundial (BANQUE MONDIALE, 1995).

Outra forma de reconhecimento da importância da prática para a formação docente é o destaque atribuído à modalidade formativa baseada em práticas de acompanhamento, que pressupõe a atuação de figuras como a do tutor, do professor formador ou do mentor na formação inicial e em serviço. Segundo Pascal Roquet (2009), o acompanhamento na formação orienta-se por uma "lógica em espiral" (p. 15) que possibilita integrá-la em um percurso individual, social e profissional, ultrapassando, assim,

etc.), nos quais também é ressaltado o teor formativo e profissionalizante da experiência prática. 
as funções tradicionais da formação. Busca-se, por essa via, superar a perspectiva aplicacionista de formação, pautada na transmissão de saberes formais e na condução dos sujeitos ao posto de trabalho pretendido. 0 acompanhamento na formação visaria, então, à construção de aprendizagens personalizadas e à apropriação de saberes de um modo plural.

Claude Dubar (1998) explica que o acompanhamento individualizado dos sujeitos na formação, e mesmo no exercício profissional, integra um modelo de gestão que emergiu nos anos 1980 na área empresarial e que prevê também outros elementos: novas normas de recrutamento que privilegiam o nível de certificação formal, como ocorre no caso da universitarização do magistério; valorização da mobilidade dos sujeitos; formação contínua criada pela própria empresa, como um dispositivo para a mobilização dos sujeitos em prol dela; multiplicação de fórmulas de individualização dos salários, como os abonos; novos critérios de avaliação que valorizam competências de terceira dimensão, ou seja, qualidades pessoais e relacionais como a responsabilidade, a autonomia, a flexibilidade e o trabalho em equipe. Nesse mesmo sentido, Maela Paul (2009) ressalta que o acompanhamento na formação está inscrito em uma lógica de autonomização centrada na pessoa, em termos de sua implicação no trabalho e responsabilização pelos resultados, que sucede à lógica anterior da expertise centrada na ação.

Além de estar em sintonia com as tendências atuais de individualização e de responsabilização dos sujeitos no mundo do trabalho, a formação pelo acompanhamento vai ao encontro também de uma demanda que se impõe para a profissionalização do magistério. A elevação de uma ocupação ao nível de profissão pressupõe, como explica Bourdoncle (2000), que seus praticantes tenham uma participação ativa na formação das novas gerações de profissionais. Isso porque a formação universitária profissional (diferentemente do que ocorre na formação geral) prevê que se possibilite aos es- tudantes a construção de uma identidade ligada à profissão para a qual os mesmos estão sendo formados. Trata-se de uma formação "extero-referente" (BOURDONCLE, 2000), ou seja, que visa ao exercício de uma profissão que se realiza e se governa no exterior da universidade. Distintamente do que ocorre na formação universitária geral, a formação profissional não pode ser definida somente pelos professores pesquisadores universitários e com a garantia de reconhecimento do diploma pelo Estado.

$\mathrm{Na}$ formação profissional, o controle da formação deve ser exercido também pelos profissionais que já estão em exercício, além de outros agentes, como os administradores e os empregadores. Então, ainda segundo Bourdoncle (2000), a formação profissional prevê a participação de agentes diversos: professores pesquisadores, inclusive os que também exercem a profissão (como no caso dos médicos e dos advogados); práticos formadores, que intervêm diretamente na formação universitária; profıssionais em exercício, que acolhem e acompanham a formação prática; e administradores do grupo profissional, consultados para os estágios, para a certificação dos formados e para sua colocação profissional.

No caso do magistério, entretanto, embora a formação profissional seja realizada com a participação de professores em exercício, no papel de tutores, mentores ou coformadores de seus pares, o grupo profissional docente não assume um controle mais efetivo nessa formação e na regulação do exercício da docência; entre outras razões, porque não conta com uma ordem profissional que exerça esse papel.

\section{Sobre triângulos, jogos e jogadores}

Nesse cenário um tanto paradoxal, em que se afirmam duas tendências, ao mesmo tempo, concorrentes e complementares - universitarização do magistério e valorização dos

2- No original francês, extéro-référencée. 
saberes experenciais dos professores -, a universidade ocupa lugar de destaque, seja como locus da formação propriamente dita (embora alternativas menos dispendiosas têm sido priorizadas), como instância de certificação e legitimação da formação oferecida em outros espaços (nos programas especiais, por exemplo) ou como instância de produção de saberes mais sofisticados e esotéricos sobre o ensino, a aprendizagem e mesmo sobre os próprios professores. A esse respeito, António Nóvoa (1999b) observa que o contexto atual é de forte desenvolvimento no campo universitário da pedagogia e das ciências da educação, envolvendo uma crescente e produtiva comunidade científico-educacional que tem nos professores e em sua prática seu foco privilegiado de estudo. Os pesquisadores universitários mostram-se cada vez mais interessados em estudar as atividades, os modos de atuação e os saberes profissionais dos professores. Com isso, tem-se em vista a produção de novos discursos científicos em educação que almejam subsidiar as mudanças pretendidas na formação dos professores e em seus processos de desenvolvimento profissional. Trata-se de discursos caracterizados, sobretudo, pela valorização dos saberes que provêm da experiência profissional e da reflexão dos professores sobre sua atuação.

Mas, apesar dessa atenção aos seus saberes e experiências profissionais e da elevação de sua formação ao nível superior, os professores dos anos iniciais continuam, como têm estado historicamente, distantes da universidade e dos demais espaços acadêmicos. Esse distanciamento é mesmo previsto nas recomendações do Banco Mundial (BANQUE MONDIALE, 1995), segundo as quais a formação docente deve ocorrer em instituições de ensino superior não universitárias, capazes de oferecer uma formação menos cara, livre das responsabilidades da pesquisa. Em tais instituições de ensino superior, não voltadas para a produção de conhecimento, os professores são colocados na posição de consumidores de produtos acadêmicos produzidos na universidade (e que, como dito antes, elegem os próprios professores, suas práticas e saberes como objetos privilegiados de estudo).

A elevação do nível de formação dos professores realizada nesses termos ocorre a distância da universidade, mas com intensa atuação desta; trata-se, portanto, de uma universitarização indireta e incompleta. Tal tipo de formação oferecida aos professores não lhes fornece subsídios para mudar sua atuação no triângulo do conhecimento proposto por Nóvoa $(1999 a)^{3}$. Esse instigante modelo baseia-se na inter-relação de três tipos de saberes que se vinculam de diferentes maneiras na produção da profıssão docente: o saber da experiência (produzido pelos professores), o saber da pedagogia (produzido pelos especialistas em ciências da educação) e os saberes das disciplinas (produzidos por especialistas dos diferentes domínios do conhecimento). Esses três tipos de saberes estão relacionados como vértices de um triângulo. No entanto, segundo Nóvoa, atualmente ocorrem ligações privilegiadas entre os dois vértices que representam os saberes de tipo científico (da pedagogia e das outras disciplinas). Essa ênfase na reflexão científica em torno da educação, com vistas a uma maior racionalização do ensino, tende a contribuir para a elevação do prestígio social do magistério. Todavia, desencadeia um processo de depreciação dos saberes produzidos pelos próprios professores, que deixam de ser reconhecidos (de fato) como produtores de saberes. Valendo-se da metáfora do jogo de bridge, anteriormente empregada por Jean Houssaye (1988) na apresentação de seu triângulo pedagógico ${ }^{4}$, Nóvoa (1999a) afirma que os professores têm assumido o lugar do morto nos discursos educacionais, ou seja,

nenhuma jogada pode ser delineada sem ter em atenção as cartas que estão em

3 - No mesmo trabalho, Nóvoa propõe também o triângulo político, formado pelo Estado, pelos pais/comunidades e pelos professores. Por meio de tal esquema, 0 autor analisa os modos de organização do sistema educativo.

4- No triângulo pedagógico, Houssaye propõe a consideração dos modelos pedagógicos a partir da interação entre três elementos: 0 sujeito que ensina, 0 aluno e conteúdo do ensino. Os mesmos elementos ocupam os vértices do triângulo didático proposto por Chevallard (1991). 
cima da mesa. Mas o jogador que as possui não pode ter uma estratégia própria: ele é o referencial passivo de todos os outros. (p. 10)

Esse modelo de análise proposto por Nóvoa auxilia-nos a perceber algumas das contradições presentes no movimento atual de profıssionalização do magistério. A intensa atividade dos especialistas em educação e nas disciplinas de ensino - que resulta em uma crescente sofısticação dos discursos pedagógicos - delineia novos horizontes profissionais para a docência. Tais discursos, como dito, enfatizam inclusive o valor das experiências e dos saberes docentes. Mas, paradoxalmente, essa valorização social docente reverte-se em maior controle sobre os professores, já que eles próprios não estão envolvidos na produção de seu novo lugar profissional.

Os professores, assumindo o lugar do morto no jogo descrito por Nóvoa, atuam como consumidores de discursos acadêmicos e de produtos formativos, tendo em vista atender às elevadas expectativas que são geradas a respeito de sua identidade, como expert, profissional reflexivo, autônomo e eficaz. Consolida-se e amplia-se, assim, um grande mercado de formação dirigido aos professores (HOLMES GROUP, 1995; NÓVOA, 1999b; MAUÉS, 2003; SARTI, 2005; SOUZA; SARTI, 2009), que vem sendo disputado por diferentes instituições e grupos científicos.

As relações que envolvem e sustentam esse mercado organizado em torno da formação docente assumem uma dimensão simbólica, no sentido proposto por Pierre Bourdieu (1996), que possibilita a transfiguração das relações de dominação presentes no campo educacional. Assim, o lugar de maior ou menor poder assumido por cada uma das instâncias envolvidas nessa disputa depende dos capitais específicos (BOURDIEU, 2005) que cada uma delas possui. É um mercado de bens simbólicos, em que atos econômicos transfiguram-se em atos simbólicos já legitimados pelos agentes que detêm capitais mais valiosos (do ponto de vista simbólico) no campo educacional (SOUZA; SARTI, 2009).
Nesse campo em disputa, manifesta-se um processo de colonização conceitual (SMYTH, 1992), que resulta em jargões e modismos educacionais. Tais jargões impõem-se como novos produtos desse mercado formativo docente e são consumidos pelos professores por meio de revistas, livros e cursos diversos, para assim se incorporarem ao seu próprio discurso. Conferem maior sofisticação ao discurso dos professores, atuando como bens simbólicos que lhes possibilitam permanecer no jogo da formação, acessando, inclusive, outros bens de consumo do mesmo mercado formativo (SOUZA; SARTI, 2009).

0 cenário que então se delineia no campo da formação de professores pode ser representado em um esquema semelhante àquele proposto por Nóvoa (1999a) para o tratamento das relações de produção de conhecimento no campo educacional. Cada um dos vértices do triângulo da formação docente aqui apresentado é ocupado por agentes que, a partir de seus capitais específicos, localizam-se em lugares desiguais nesse campo: os professores e as instâncias que os representam; as universidades, fundações e institutos de pesquisa, com seus especialistas; e o poder público, representado por secretarias de educação e outros órgãos administrativos. Relações privilegiadas entre dois vértices desse triângulo apontam para diferentes modelos de formação docente.

\section{Três configurações possíveis do triângulo da formação docente}

Como antes mencionado, o movimento atual de profissionalização dos professores corresponde a uma estratégia empregada pelos Estados para ajustar a escola ao padrão de eficiência previsto no modelo econômico vigente, de orientação neoliberal. Segundo a abordagem funcionalista que orienta esse processo em curso, a profissionalização de uma ocupação pressupõe, necessariamente, a elevação do nível de formação daqueles que a exercem, bem como a formação de um corpo 
de conhecimentos especializados, necessário para a realização das tarefas que a compõem (BOURDONCLE, 2000). A universidade desempenha, então, importante papel nesse processo e, devido à elevação do nível da formação docente e da sofisticação dos discursos pedagógicos, os segmentos acadêmicos atuantes nesse campo vivem hoje um momento de efervescência. Observa-se atualmente, pois, o estabelecimento de relações bastante privilegiadas entre dois dos vértices que compõem o triângulo da formação docente: poder público e universidade (relação que também inclui fundações e outros institutos ligados à pesquisa).

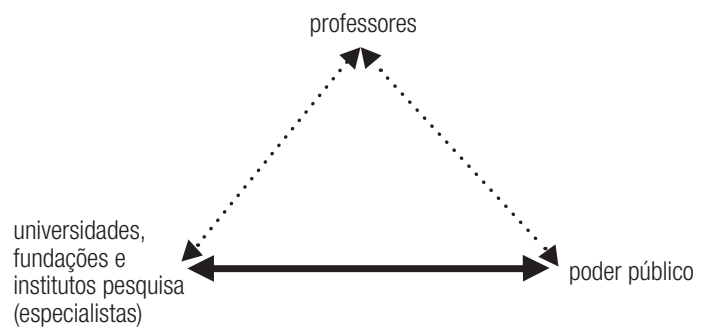

No caso brasileiro, esse estreitamento das relações entre poder público e universidade para a formação docente revela-se, por exemplo, nos programas especiais de formação de professores em serviço que, como já citado, foram implementados em diferentes localidades do país. Outra iniciativa que aponta para tal vinculação é o estabelecimento, pela Coordenadoria de Aperfeiçoamento de Pessoal de Nível Superior (CAPES), do Plano Nacional de Formação de Professores da Educação Básica (BRASIL, 2009), o qual, seguindo por caminho aberto pelos programas especiais, prevê ação conjunta do Ministério da Educação, de instituições de educação superior (municipais, estaduais, comunitárias e confessionais) e de secretarias de educação dos Estados e municípios. Por meio desse plano, pretende-se oferecer, de um lado, formação em nível superior aos professores em exercício das redes estaduais e municipais que ainda não possuem diploma de graduação e, de outro, licenciatura para professores (graduados) que ainda não a possuem ou que, mesmo tendo cursado uma primeira licenciatura, atuam fora de sua área de formação. 0 plano prevê o oferecimento de cursos na modalidade presencial e a distância.

No entanto, cabe reiterar que essa aproximação entre poder público e universidade não tem resultado em um movimento mais expressivo de universitarização do magistério. Muitas vezes, a formação oferecida aos professores não ocorre em ambientes universitários, revertendo-se numa formação em

nível pós-secundário, ou seja, superior, mas sem obedecer necessariamente aos princípios básicos que caracterizam a instituição universitária desde o seu surgimento, pelo menos como universidade moderna, no início do século XIX, ou seja, o ensino ligado à pesquisa, à autonomia em relação a ensino e pesquisa e à socialização dos conhecimentos. (MAUÉS, 2003, p. 100)

Nesses casos, ocorre uma "falsa universitarização” (BOURDONCLE, 2007, p. 139) e mesmo uma secundarização da formação docente (SARTI; BUENO, 2007). Essa secundarização revela-se em dois sentidos complementares: no que se refere às práticas formativas oferecidas aos professores e ao baixo valor simbólico que tal formação alcança na hierarquia social.

Considera-se que esse tipo de parceria entre o poder público e as universidades para o oferecimento de formação docente reflete um conjunto de concepções, expectativas e interesses sobre a formação inicial e em serviço dos docentes que se inscreve em um movimento de fabricação do professor profissional (POPKEWITZ; NÓVOA, 2001), ancorado em um modelo de formação que "privilegia a racionalidade instrumental, fundada na coerência entre os meios e os fins" (BOURDONCLE, 1990, p. 66). Como ressalta Bourdoncle (1990), nessa formação são enfatizados os saberes diretamente aplicáveis na prática, negligenciando-se, assim, aspectos da teoria educacional e o aprofundamento disciplinar. 
Assim, embora a universidade ocupe um lugar de destaque nesse modelo formativo, ela não logra em garantir uma formação docente realmente universitária. A formação de fato oferecida aos professores baseia-se em uma perspectiva técnico-instrumental (LENOIR, 2004) resultante das relações de poder estabelecidas entre a universidade e o poder público, o qual, por sua vez, como já mencionado, está ligado a políticas educacionais definidas internacionalmente. 0 que temos como resultado dessa aproximação entre universidade e poder público é a configuração de um modelo de competências na formação docente, que implica novos desafios para o trabalho na universidade e, possivelmente, mudanças na identidade de seus docentes pesquisadores.

Transposta do mundo empresarial para a educação, a noção de competência tem sido incorporada por discursos que propõem mudanças no que se refere ao modo de pensar os conteúdos do ensino e, principalmente, de organizar as práticas docentes. Viviane Isamberti-Jamati (1997) explica que, ao longo da década de 1990, o emprego do termo competência tornou-se cada vez mais frequente entre os especialistas das ciências sociais, que passaram a utilizá-lo no plural, para designar os conteúdos particulares de cada qualificação em uma organização de trabalho.

Aplicado a assuntos educacionais, o termo integra um tendência de "hiper-racionalização do ensino e da aprendizagem” (ROPÉ, 1997, p. 81), por meio de esforços para a decomposição de tarefas, a explicitação de critérios e a padronização das situações educativas, a exemplo do que é considerado desejável em diversos ramos do mundo do trabalho. Busca-se objetivar e racionalizar o contrato pedagógico a partir do pressuposto tecnocrático de que tudo seja observável e mensurável. Esses esforços de “formalização pedagógica” (TANGUY, 1997, p. 50) visam atender à cultura da avaliação que já há alguns anos ressurgiu com força no cenário educacional. A proposição de referenciais ou padrões de ação para os professores, com a decomposição de suas práticas e posturas, pre- tende conferir maior objetividade ao ensino, de modo a torná-lo passível de avaliações mais precisas. Segundo os padrões estabelecidos, o professor mais bem avaliado é o profissional capaz de gerenciar seu trabalho, participar na administração da escola e administrar, inclusive, sua própria formação continuada. Tem-se, assim, que a busca por racionalidade e produtividade nesse contexto coexiste e é, de certo modo, complementada pela proclamação da autonomia e da profissionalização docente.

Pensado nesses termos, o movimento de profissionalização do magistério atualmente em curso não parece atender aos anseios dos professores, que são considerados como referenciais passivos do processo de profissionalização de seu ofício, ocupando o lugar de consumidores de discursos e produtos formativos que lhes são propostos para a formação continuada e/ou em serviço.

Ademais, como dito antes, a formação e a entrada na carreira das novas gerações docentes são processos externos ao magistério. São as instituições de ensino superior que organizam seus currículos, a partir de referenciais propostos pelos órgãos administrativos centrais. A formulação desses referenciais norteadores, por sua vez, baseia-se em documentos de organismos internacionais, contando com reduzida participação de entidades que representam o magistério e mesmo da comunidade acadêmico-educacional. Nesse sentido, até a inserção dos profissionais docentes na formação de seus pares - na figura de tutores, coformadores, mentores etc. - depende da iniciativa das instituições de formação e dos órgãos centrais ${ }^{5}$. 0 ingresso dos professores na carreira docente, após a formação inicial no nível superior, ocorre por meio de concursos organizados pelo poder público ou por entidades privadas, sem a participação direta dos professores que, como mencionado, não contam com uma ordem profissional que os represente.

5 - No caso brasileiro, a CAPES criou o Programa Institucional de Bolsa de Iniciação à Docência (PIBID), que prevê a participação de professores coformadores na orientação dos estágios de estudantes de licenciatura (BRASIL, 2007). 
Poder público e especialistas da educação (ligados a universidades, institutos e fundações de pesquisa e/ou a organismos internacionais) vêm, assim, alcançando êxitos bastante significativos nas disputas atualmente estabelecidas no campo educacional, no que se refere ao monopólio da autoridade (BOURDIEU, 2003) e da competência para estabelecer o que os professores devem saber, como devem agir profissionalmente, onde, como e por quem devem ser formados. Aos professores e às entidades que os representam resta um lugar marginal no processo. Atuam como o morto no jogo da formação docente, um referencial passivo para os demais jogadores cuja existência, no entanto, possibilita todas as jogadas.

Mas essa não é a única configuração possível para o triângulo da formação docente. Há outros dois lados do triângulo a serem considerados. Relações privilegiadas entre poder público e magistério caracterizaram a formação oferecida pelas Escolas Normais; um modelo de formação carismático (BOURDONCLE, 1990) por meio do qual o Estado, assumindo a educação do povo, buscava preparar seus professores para que eles difundissem, juntamente com os conhecimentos escolares, qualidades morais relacionadas a certos modos de agir, pensar e sentir.

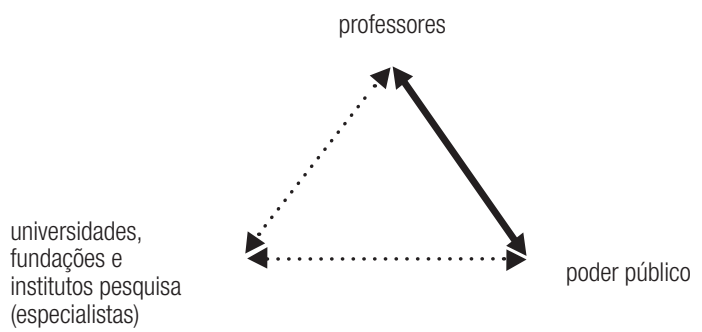

Referindo-se mais especificamente ao caso francês - principal inspiração para a Escola Normal implementada entre nós (TANURI, 2000) -, Bourdoncle (1990) explica:

para se tornarem, em nome do Estado, educadores do povo, os alunos-professores deveriam adquirir, eles mesmos, as qualidades esperadas e mostrarem-se exemplares. As
Escolas Normais os preparava de duas maneiras: indireta, pela organização da vida interna, e direta, por um ensino específico garantido pelo diretor. (p. 61, tradução nossa)

Nesse sentido, objetivava-se que, nos anos que passasse na Escola Normal, sob um modelo carismático (BOURDONCLE, 1990), artesanal (LANG, 1996) e didático-pedagógico (SAVIANI, 2009) de formação de professores, o normalista elaborasse uma nova identidade, fortemente vinculada ao magistério em diversos planos:

em suas concepções, guiadas pela razão e pela ciência; em suas faculdades de memória, julgamento, raciocínio e inteligência, que ele aprende a desenvolver em si mesmo para poder desenvolver nas crianças; em suas paixões, enfım, que a disciplina da escola normal, a aquisição de hábitos de trabalho e um modo de vida regular e moralmente exigente lhe terão permitido dominar. (BOURDONCLE, 1990, p. 61, tradução nossa)

Uma “educação total” (p. 61), realizada em um ambiente marcado por relações interpessoais fortes, mantidas com personalidades exemplares, encarnadas especialmente pelo diretor, mas também pelos professores. Essa "forma de transmissão artesanal” (p. 59) permitia, por meio da imitação do mestre, a aquisição de técnicas e de saberes práticos, favorecendo também, pela identificação, a adesão a valores específicos do meio profissional.

Nesse tipo de formação, pautada por certo "conservantismo social” (LANG, 1996, p. 9) e pela reprodução de práticas consideradas eficazes, o ensino revela-se como uma atividade eminentemente prática, subsidiada principalmente por saberes advindos da tradição pedagógica e da experiência pessoal. Os saberes disciplinares e as instâncias que os produzem por meio da pesquisa científica ocupavam, pois, o lugar do morto no jogo da formação ${ }^{6}$.

6 - No Brasil, a superação desse modelo artesanal de formação foi buscada por meio de iniciativas como a criação de Institutos de Educação, nos anos 
Uma terceira configuração possivel desse triângulo resulta de uma ligação mais estreita entre universidade e professores.

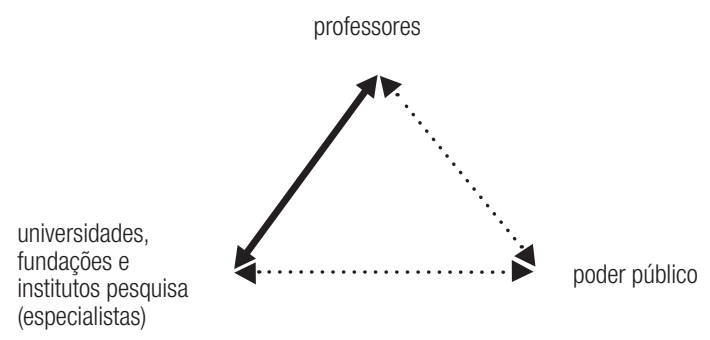

É possivel pensar que tal ligação apontaria para a já referida universitarização do magistério, empreendida em diferentes países ao longo do século XX e que continua a orientar novas reformas na formação dos professores. Mas, como visto, é da relação entre universidade e poder público que tem resultado esse movimento de universitarização, com suas diversas contradições. E, embora uma maior aproximação entre professores da escola básica e universidade constitua aspiração antiga ${ }^{7}$, frequentemente apontada no discurso educacional, trata-se de um assunto que merece exame atento, posto que esses dois vértices do triângulo têm-se mantido historicamente distantes e sua aproximação na formação docente impõe desafios diversos.

Primeiramente, faz-se necessário considerar que tais vértices são ocupados por duas culturas profissionais distintas. A cultura profissional partilhada no ambiente universitário está ancorada em valores e práticas acadêmicas que alcançam legitimidade social suficiente para nomear, descrever e explicar teoricamente fenômenos relacionados ao ensino, à aprendizagem, ao trabalho docente e à instituição escolar. Alguns fatores assumem destaque no seio dessa cultura profissional: a proximidade com disciplinas científıcas de diferentes áreas e a produção e divulgação de saberes prioritariamente por meio

1930, com o intuito de estabelecer um modelo de formação calcado em uma pedagogia nova, científica e experimental (CARVALHO, 2000).

7 - Presente, por exemplo, no Manifesto dos Pioneiros da Educação Nova (AZEVED0, 1932). da escrita, o que implica modos específicos de comunicação e de relação entre os grupos.

Os professores, por sua vez, estão filiados a uma cultura profissional vinculada ao trabalho cotidiano escolar, pela ação diante dos eventos e das muitas urgências impostas à vida ordinária institucional e, portanto, pelo interesse em informações que lhes auxiliem a tomar decisões sobre esses acontecimentos que se sucedem cotidianamente. A circulação de tais informações entre os professores baseia-se, especialmente, na comunicação oral entre os pares e na consulta de obras práticas (ETÉVÉ; HASSENFORDER; LAMBERT-CHESNOT, 1988; CHARTIER, 1998).

Tem-se, pois, que os tipos de saberes mais valorizados pelos professores, as formas pelas quais tais saberes são compartilhados entre eles e as atividades a que eles se dedicam profissionalmente gozam de menor prestígio social que os saberes, as práticas e os interesses desinteressados ${ }^{8}$ dos universitários. Essa desigualdade entre professores da escola e professores-pesquisadores da universidade tem dificultado o estabelecimento de relações mais estreitas e recíprocas entre eles no triângulo da formação docente.

A própria ideia de universitarização traz subjacente uma desigualdade de posições, sugerindo que a formação dos professores deva ser absorvida e transformada pela cultura universitária. Afirma Bourdoncle (2007):

Podemos dizer que há universitarização quando as instituições de transmissão de saberes de um setor profissional, os próprios saberes e os formadores que os transmitem acham-se, de algum modo, absorvidos pela universidade. (p. 138, tradução e grifos nossos)

Sobre cada um desses três aspectos, o autor esclarece:

8 - De acordo com Pierre Bourdieu (1996), o campo científico constitui um dos microcosmos onde o desinteresse (econômico, prático) é recompensado. Seus agentes, devido a seu habitus, conhecem interesses de outra natureza que são específicos ao jogo da produção científica. 
- as instituições de formação de origem desaparecem ou são profundamente transformadas em função das estruturas universitárias habituais e de seus modos ordinários de funcionamento;

- os saberes profissionais são não apenas transmitidos, mas também criados e acumulados segundo as regras particulares da universidade, reservando um amplo espaço para a atividade de pesquisa;

- os encarrergados da formação veem-se confrontados com um novo estatuto dominante, aquele de professor-pesquisador, para o qual é exigido um doutorado. (BOURDONCLE, 2007, p. 138, tradução nossa)

Em um processo desse tipo, não resta muito espaço para a cultura do magistério e para uma participação mais ativa dos professores da escola. Como visto, é com o outro vertice do triângulo que a universidade se alia em tal processo, enquanto os professores atuam no papel do morto.

\section{A terceira configuração do triângulo: entre desafios e possibilidades}

Uma formação resultante de ligações mais estreitas entre professores da escola e universidade teria de conferir espaço e legitimidade para o modo de vida e a cultura presentes nesses dois vértices do triângulo. Impor-se-iam, nesse caso, diferentes desafios. Primeriamente, o desafio de melhor articular a busca pela compreensão dos fatos educativos com a delicada apredizagem da docência, numa relação mais clara e profícua entre a prática sistemática de teorizar e a prática de ensinar, considerando e problematizando os saberes que as duas instâncias envolvidas produzem sobre essas duas práticas sociais. Do mesmo modo, tal formação seria pautada em relações mais dialéticas entre inovação e tradição e entre oralidade e escrita.

Para tanto, seriam necessários novos critérios para a defınição do estatuto dos diferentes agentes envolvidos diretamente na formação docente: professores pesquisadores, práticos formadores, profissionais que acolhem os estudantes nos estágios curriculares e administradores do grupo profissional. 0 desempenho de um papel ativo na formação docente por parte desses profissionais ligados mais diretamente ao exercício da docência é, como antes mencionado, condição para a profissionalização do magistério, cujas referências profissionais são exteriores à universidade (BOURDONCLE, 2000).

Há, ainda, outro desafio que se coloca para o estreitamento das ligações entre professores da escola e universidade no jogo da formação docente. Como nas outras duas possibilidades de configuração do triângulo da formação, tal ligação implica que o ocupante do vértice oposto assuma um lugar de menor destaque. Nesse caso, o poder público passaria ao lugar do morto, estando presente no jogo, mostrando suas cartas, mas não podendo interferir no desenrolar das ações; algo bastante distante da função reguladora assumida pelos Estados atualmente. É necessário explorar tal caminho no sentido de precisar melhor os contornos do lugar do morto nesse caso e de recriá-lo conforme as necessidades do jogo.

A produção de um novo modelo de formação docente, resultante da união inédita entre dois vertices do triângulo da formação - professores da escola e professores da universidade - que historicamente mantêm frágeis ligações, requer exame rigoroso das possibilidades de aproximação já existentes. Faz-se necessário, então, empenhar esforços para identificar, no modelo de formação docente que ora se impõe, a atuação dos agentes envolvidos e os movimentos de aproximação que já ocorrem entre eles, embora sob as regras do jogo atualmente jogado. Estudos sobre propostas e práticas de universitarização do magistério podem oferecer informações relevantes, por exemplo, sobre as maneiras pelas quais os professores desempenham os papéis que lhes são atribuídos no jogo (todos eles, supõe-se, ligados ao lugar do morto); mais precisamente, sobre suas operações 
quando os consideramos entregues à disciplina e à passividade. Tal empresa requer, como propõe Michel de Certeau (1994),

exumar os modelos de ação característicos dos usuários, dos quais se esconde, sob o pudico nome de consumidores, o estatuto de dominados (o que não quer dizer passivos ou dócieis). (p. 38)

Que operações realizam os professores quando se aproximam da universidade, seja como alunos dos cursos de formação (em programas especiais, por exemplo) ou na condição de formadores de futuros professores, tal como previsto nas práticas de acompanhamento? Sobre a primeria situação, mais explorada entre nós, alguns estudos revelam que, ao se tornarem alunos da universidade, os professores tendem a assumir posturas e ações de ordem tática (DE
CERTEAU, 1994), subvertendo a formação que lhes é oferecida para: poderem afırmar o valor de seus próprios saberes profissionais diante da cultura acadêmica (SARTI, 2005; SENE, 2010), atribuírem sentidos imprevistos às experiências formativas então vivenciadas (OLIVEIRA, 2009), ou simplesmente garantirem sua sobrevivência (SENE, 2010) nesse ambiente que lhes é estranho e desafiante.

Tais informações sobre as maneiras de fazer dos professores na universidade possibilitam-nos problematizar a hipótese de sua passividade como o morto no jogo da formação docente. Estudos nessa direção permitem-nos compreender melhor como os professores apropriam-se do modelo de formação docente em vigor e convidam-nos ao questinamento: mesmo ocupando o lugar do morto, são os professores capazes de alterar esse modelo estabelecido, produzindo silenciosamente um jogo diferente? 


\section{Referências}

AZEVEDO, Fernando de. A reconstrução da Educação no Brasil: ao povo e ao governo - Manifesto dos Pioneiros da Educação Nova. São Paulo: Editora Nacional, 1932.

BANQUE MONDIALE. Priorités et stratégies pour l'éducation: une étude de la Banque Mondiale. Washington: Banque Mondiale, 1995.

BELLO, Isabel Melero. Formação superior de professores em serviço: um estudo sobre o processo de certificação do magistério brasileiro. 2008. Tese (Doutorado) - Faculdade de Educação, Universidade de São Paulo, São Paulo, 2008.

BOURDIEU, Pierre. Razões práticas: sobre a teoria da ação. 7. ed. Campinas: Papirus, 1996.

0 campo científico. In: ORTIZ, Renato (Org.). A sociologia de Pierre Bourdieu. São Paulo: Olho d’Água, 2003. p. 112-143.

. Razões práticas: sobre a teoria da ação. 7. ed. Campinas: Papirus, 2005.

BOURDONCLE, Raymond. De l'instituteur à l'expert. Les IUFM et l'évolution des instituitions de formation. Recherche et formation, Paris, n. 8, p. 57-72, 1990.

. Professionnalisation, formes et dispositifs. Recherche et formation, Paris, n. 35, p. 117-132, 2000.

. Univesitarisation. Recherche et formation, Paris, n. 54, p. 135-49, 2007.

BRASIL. Ministério da Educação. Lei de Diretrizes e Bases da Educação Nacional, Brasília, 1996.

BRASIL. Ministério da Educação. Secretaria da Educação Fundamental. Referenciais Nacionais para a Formação de Professores. Brasília, DF: MEC/SEF, 1999.

BRASIL. Ministério da Educação. Resolução CNE/CP nº 1, de 18 de fevereiro de 2002. Institui Diretrizes Curriculares Nacionais para a Formação de Professores da Educação Básica, em nível superior, curso de licenciatura, de graduação plena. Diário Oficial da União, Brasilia, DF, 9 abr. 2002. Seção 1, p. 31.

. Resolução CNE/CP nº 1, de 15 de maio de 2006. Institui Diretrizes Curriculares Nacionais para o Curso de Graduação em Pedagogia, licenciatura. Diário Oficial da União, Braślia, DF, 16 maio 2006. Seção 1, p. 11.

Portaria normativa $n^{0}$ 38, de 12 de dezembro de 2007. Dispõe sobre o PIBID - Programa Institucional de Bolsa de Iniciação à Docência. Diário Oficial da União, Brasília, DF, 13 dez. 2007. Seção 1, p. 39.

. Decreto $n^{0}$ 6.755, de 29 de janeiro de 2009. Institui a Política Nacional de Formação de Profissionais do Magistério da Educação Básica, disciplina a atuação da Coordenação de Aperfeiçoamento de Pessoal de Nível Superior - CAPES no fomento a programas de formação inicial e continuada, e dá outras providências. Diário Oficial da União, Brasília, DF, 30 jan. 2009. p. 1.

BUENO, Belmira Oliveira. É possível reinventar os professores? A "escrita de memórias" em um curso espacial de formação de professores. In: SOUZA, Elizeu Clementino de; ABRAHÃO, Maria Helena M. Barreto (Orgs.). Tempos, narrativas e ficções: a invenção de si. v. 1. Porto Alegre; Salvador: EDIPUCRG; UFBA, 2007. p. 219-238.

CARVALHO, Marta Maria Chagas de. Modernidade pedagógica e modelos de formação docente. São Paulo em Perspectiva, São Paulo, v. 14, n. 1, jan./mar. 2000.

CHARTIER, Anne-Marie. Expertise enseignante entre savoirs pratiques et savoirs théoriques. Recherche et Formation, Paris, $n$. 27, p. 67-82, 1998.

A questão da língua materna na formação continuada entre os anos 1970 e 2010 na França. In: FERREIRA, Andrea Tereza Brito; CRUZ, Shirleide P. da Silva (Orgs.). Formação continuada de professores: reflexões sobre a prática. Recife: Editora da UFPE, 2010. p. 53-67. 
CHEVALLARD, Yves. La transposition didactique: du savoir savant au savoir enseigné. 2. ed. Grenoble: La Pensée Sauvage, 1991. DE CERTEAU, Michel. A invenção do cotidiano: artes do fazer. 6. ed. Petrópolis: Vozes, 1994.

DUBAR, Claude. A sociologia do trabalho frente à qualificação e à competência. Educação e Sociedade, Campinas, v. 19, n. 64, p. 87-103, set. 1998.

ETEVE, Christiane; HASSENFORDER, Jean; LAMBERT-CHESNOT, Odile. Des enseignants leaders d'opinion: une minorité cachée? Perspectives Documentaires en Education, Paris, n. 15, p. 129-31, 1988.

HOLMES GROUP. Tomorrow's schools of education. East Lansing, MI: Holmes Group, 1995.

HOUSSAYE, Jean. Triangle pédagogique: théorie et pratiques de l'éducation scolaire. Bern: Editions Peter Lang, 1988.

ISAMBERT-JAMATI, Viviane. 0 apelo à noção de competência na revista L'Orientation Scolaire et Professionnelle: da sua criação aos dias de hoje. In: ROPÉ, Françoise; TANGUY, Lucie (Orgs.). Saberes e competências: 0 uso de tais noções na escola e na empresa. Campinas: Papirus, 1997. p. 103-33.

LANG, Vincent. Professionnalisation des enseignants, conceptions du métier, modèles de formation. Recherche et Formation, Paris, n. 23, p. 9-27, 1996.

LENOIR, Yves. L'enseignant expert: regard critique sur une notion non dépourvue d'interêt pour la recherche sur les pratiques enseignantes. Recherche et Formation, Paris, n. 47, p. 9-23, 2004.

MAUÉS, Olgaíses Cabral. Reformas internacionais da educação e formação de professores. Cadernos de Pesquisa, São Paulo, n. 118, p.89-118, mar. 2003.

NÓVOA, António (Org.). Profissão Professor. 2. ed. Porto: Porto Ed., 1999a.

Os professores na virada do milênio: do excesso dos discursos à pobreza das práticas. Educação e Pesquisa, São Paulo, v. 25, n. 1, p. 11-20, jan.-jun. 1999b.

OLIVEIRA, Adolfo Samuel de. Quando o professor se torna aluno: tensões, desafios e potencialidades da formação em serviço. Dissertação (Mestrado em Educação) - Faculdade de Educação, Universidade de São Paulo, São Paulo, 2009.

PAUL, Maela. Autour du mot accompagnement. Recherche et Formation, Paris, n. 62, p. 91-108, 2009.

POPKEWITZ, Thomas S.; NÓVOA, António. La fabrication de l'enseignant professionnel: la raison du savoir. Recherche et Formation, Paris, n. 38, p. 5-13, 2001.

ROPÉ, Françoise. Dos saberes às competências? 0 caso do francês. In: ROPÉ, Françoise; TANGUY, Lucie (Orgs.). Saberes e competências: 0 uso de tais noções na escola e na empresa. Campinas: Papirus, 1997. p. 21-30.

ROQUET, Pascal. L'emergence de l'accompagnement: une nouvelle dimension de la formation. Recherche et Formation, Paris, n. 62, p. 13-24, 2009.

SARTI, Flavia Medeiros. Leitura profissional docente em tempos de universitarização do magistério das séries iniciais. Tese (Doutorado em Educação) - Faculdade de Educação, Universidade de São Paulo, São Paulo, 2005.

SARTI, Flavia Medeiros; BUENO, Belmira Oliveira. Leituras profissionais docentes e apropriação de saberes acadêmico-educacionais. Cadernos de Pesquisa, São Paulo, v. 37, n. 131, p. 455-479, maio/ago. 2007.

SAVIANI, Dermeval. Formação de professores: aspectos teóricos e históricos do problema no contexto brasileiro. Revista Brasileira de Educação, v. 14, n. 40, p. 143-155, jan./abr. 2009.

SENE, Daniela G. Alfredo. Rotas alternativas: histórias de professoras que não puderam cursar os Programas Especiais de Formação Pedagógica Superior em São Paulo. Dissertação (Mestrado em Educação) - Faculdade de Educação, Universidade de São Paulo, São Paulo, 2010. 
SMYTH, John. Teachers' work and the politics of reflection. American Educational Research Journal, v. 29, n. 2, p. 267-300, 1992.

SOUZA, Denise Trento Rebello de; SARTI, Flavia Medeiros. Mercado de formação docente: origens, dispositivos e consumidores. In: ENCONTRO DE PESQUISA EM EDUCAÇÃO DA REGIÃO SUDESTE (ANPED- Sudeste), 9., 2009, São Carlos. Anais... São Carlos: UFSCAR, 2009. CD-ROM, v. 1, p. 1-13.

TANGUY, Lucie. Racionalização pedagógica e legitimação política. In: ROPÉ, Françoise; TANGUY, Lucie (Orgs.). Saberes e competências: 0 uso de tais noções na escola e na empresa. Campinas: Papirus, 1997. p. 121-135.

TANURI, Leonor Maria. História da formação de professores. Revista Brasileira de Educação, n. 14, p. 61-88, maio/jun./ago. 2000.

TARDIF, Maurice. Saberes docentes e formação de professores. 6. ed. Petrópolis: Ed. Vozes, 2002.

Recebido em: 03.02.2011

Aprovado em: 22.09.2011

Flavia Medeiros Sarti é professora da Universidade Estadual Paulista, campus de Rio Claro, doutora em Educação pela Faculdade de Educação da Universidade de São Paulo, e desenvolve pesquisas sobre formação de professores e profissão docente. 